\title{
Adaptación de la Técnica de Impregnación Argéntica de Llombart para la Demostración de Fibras Nerviosas, en Cualquier Tejido en Cortes por Parafina
}

\author{
Adaptation of Llombart's Silver Impregnation Technique for Demonstration \\ of Nerve Fibers in Any Tissue in Paraffin Sections
}

Patricia Rivas Manzano*; Carlos Tonatiuh Chavira Ramírez* \& Rosario Ortiz Hernández **

RIVAS, M. P.; CHAVIRA, R. C. T. \& ORTIZ, H. R. Adaptación de la técnica de impregnación argéntica de Llombart para la demostración de fibras nerviosas, en cualquier tejido en cortes por parafina. Int. J. Morphol., 32(3):973-980, 2014.

RESUMEN: En la investigación biológica sigue siendo necesaria la demostración de la inervación periférica en numerosos tejidos y órganos. El objetivo de este trabajo fue rescatar y modernizar uno de los métodos más constantes que hemos probado para demostrar la inervación periférica. La técnica de Llombart para fibras nerviosas se adaptó en cortes por parafina de $7 \mu \mathrm{m}$ en diferentes tejidos animales. La impregnación argéntica se hizo por goteo en cámara húmeda. Se demostraron en forma constante, precisa y seriada terminaciones nerviosas y corpúsculos sensoriales, neuronas y fibras nerviosas periféricas. A pesar de la alta especificidad para fibras nerviosas, la técnica no compromete el panorama tisular por lo que da bellas imágenes de conjunto. Sin ser una técnica para argentafinidad, demuestra claramente dos tipos de células argentafines en las glándulas adrenales. La adición de los reactivos metálicos en gotas y en cámara húmeda, ofrece una variante sumamente económica.

PALABRAS CLAVE: Impregnación argéntica; Fibras nerviosas; Inervación periférica; Células argentafines.

\section{INTRODUCCIÓN}

El año 2006, la celebración del centenario del otorgamiento del Premio Nobel a Cajal y Golgi, hizo reflexionar a la comunidad científica sobre los aportes de estos genios a la ciencia moderna. El premio Nobel fue posible en parte gracias a que Golgi en 1873, descubrió un novedoso método histológico para impregnar una célula nerviosa completa. Años después Cajal definió más estrictamente las condiciones de la reacción cromoargéntica del método de Golgi y así estableció con claridad y precisión el plan fundamental de la estructura histológica del Sistema Nervioso (De Carlos \& Borrell, 2007).

En la actualidad, los neurocientíficos soportados en los hombros de estos dos gigantes (Jacobson, 1996) y con poderosas herramientas tecnológicas, están empezando a observar, a 80 años de la muerte de Cajal, un horizonte más allá del observado por él.

El mapeo del cerebro con técnicas de impregnación argéntica fue seguido por el mapeo de los neurotransmisores que identifican sistemas neuronales y por el mapeo de los receptores para los neurotransmisores (Kuhar et al., 1985). Todos estos trabajos proveyeron a los neurocientíficos con un mapa neuroanatómico y químico detallado del cerebro. Esta información tuvo su mayor impacto cuando los análisis de imagen asistidos por computadora se hicieron posibles (Fuxe \& Agnati, 1985).

Como sabemos, de manera natural, a mediados del Siglo XX, las técnicas argénticas empezaron a caer en desuso a la par del surgimiento de nuevas tecnologías de marcaje celular muy específicas. Además, se les etiquetó de caprichosas o de difícil manejo, por la facilidad con que la plata precipita, y al requerirse manos expertas para realizarlas fueron abandonándose poco a poco.

Una revitalización para los métodos argénticos fue el descubrimiento por Nauta (1952) de que la oxidación con permanganato de potasio por corto tiempo sobre cortes de tejido fijado en formol, suprime la argirofilia de las fibras

\footnotetext{
* Departamento de Biología Comparada. Facultad de Ciencias, Universidad Nacional Autónoma de México (UNAM), México D.F., México.

** Departamento de Biología Celular, Facultad de Ciencias, Universidad Autónoma de México (UNAM), México D.F., México.
} 
normales, mientras que las degeneradas permanecen visibles. Posteriormente se encontró que estos métodos supresivos podían marcar también los cuerpos neuronales en degeneración. Esta posibilidad sigue dando a estos métodos un lugar importante entre las herramientas comunes para identificar degeneración nerviosa en traumas, enfermedades y toxicidad. Otros métodos argénticos se siguen refinando para marcar degeneración no desintegrativa, como las placas y las marañas de la enfermedad de Alzheimer (Switzer, 2000). Entre estos tenemos el método de Bielschowsky y sus variantes, que se aplican tanto en cortes por congelación como incluidos en parafina. Esta última opción, permitió extender su uso en los estudios de rutina.

Con el mismo principio de acción que el de Bielschowsky (Fig. 1), el método de Llombart es una técnica muy constante y precisa para la demostración de fibras y terminaciones nerviosas centrales y periféricas. Se basa en una doble impregnación con soluciones de plata concentradas. La primera impregnación sensibiliza al tejido para que la segunda impregne de manera selectiva, las fibras nerviosas. Entre ambas impregnaciones se realiza la reducción con formol al $25 \%$ sin lavados interpuestos.

Como puede verse en el esquema los pasos fundamentales de esta impregnación son sensibilizar, impregnar y reducir.

Sensibilizar, es preparar al tejido para favorecer el depósito selectivo de la plata en algunas estructuras. Los sensibilizadores pueden ser de muy diversa naturaleza como el amoníaco, el permanganato de potasio $\left(\mathrm{KMnO}_{4}\right)$ o la misma plata (técnicas de Bielschowsky y Llombart), que ayu- dan para activar los sitios de reducción dentro del tejido (Kiernan, 2010).

Impregar, consiste en el depósito de metales en los elementos tisulares o celulares. El nitrato de plata $\left(\mathrm{AgNO}_{3}\right)$ es el más utilizado debido a la formación de iones de plata simples $(\mathrm{Ag}+)$, o iones complejos tales como diamina de plata $\left[\mathrm{Ag}\left(\mathrm{NH}_{3}\right) 2\right] \mathrm{NO}_{3}$ o Nitrato de Plata Amoniacal, que se forma por la adición de hidróxido de amonio a la solución de nitrato de plata (Grizzle, 1996; Kiernan, 2010).

Reducir, significa convertir la plata ionizada (Ag+) a plata metálica $(\mathrm{Ag})$. Algunos componentes celulares o tisulares tienen la capacidad por si mismos de hacer dicha reducción (argentafines) y la reacción se denomina argentafinidad. Otros elementos son argirófilos y requieren de un reductor externo como el formol o la luz y a la reacción se le llama argirofilia (Grizzle).

Opcionalmente se puede realizar la Entonación áurica para cambiar el color que resulta del proceso de reducción de la plata (color café, marrón o negra y el fondo dorado), al ser sustituidos los depósitos de plata por depósitos de oro metálico, que son de color púrpura al tratar el tejido con cloruro de oro $\left(\mathrm{AuCl}_{3}\right)$. El oro metálico se deposita en partículas más pequeñas y es mucho más estable que la plata metálica, y los cortes tratados con esta solución muestran un mejor contraste, claridad y nitidez de las estructuras, que los que no han sido tratados con esta solución.

El Dr. Antonio Llombart, perteneció al grupo de histopatólogos que entre los años 1950-70 usaban la plata para hacer investigación neurocientífica en España junto con

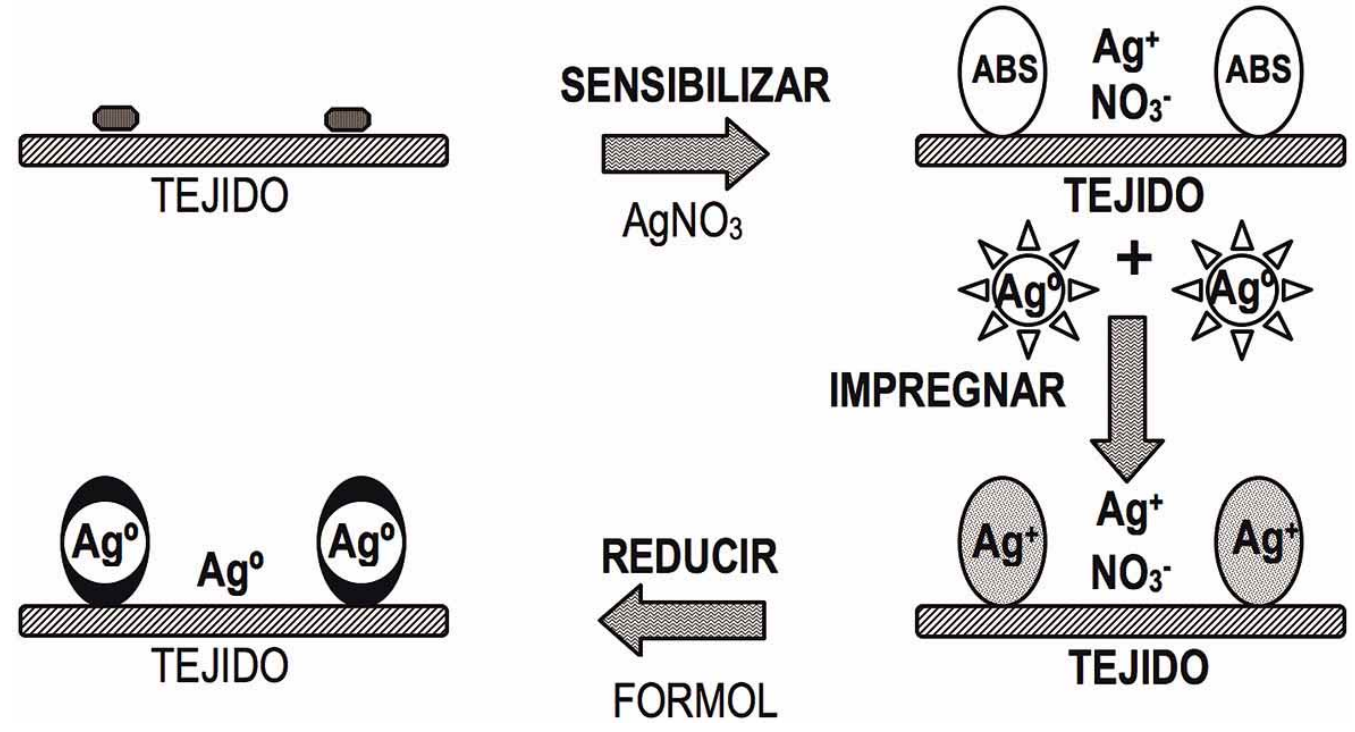

Fig. 1. Esquema de la impregnación tipo II (Bielschowsky) de acuerdo a sus principios fisicoquímicos. El principio básico es el mismo en la técnica de Llombart. Modificado de Grizzle 1996. 
Oliva, Jabonero y Bullón. Otros grupos en el mundo estaban en Argentina (Polak), en Panamá (Herrera), en México (Costero y Nieto) y en Estados Unidos (Sharemberg, Liss y Pomerat) (Costero, 1977).

Es lógico que en la era de la Biología molecular y de las nuevas tecnologías computacionales, las técnicas morfológicas hayan visto reducida su aplicación (Peters, 2007). La demostración especifica de genes, moléculas, estructuras subcelulares, etc., ha permitido un notable avance de las neurociencias. Sin embargo la importancia que los propios avances tecnológicos han aportado sobre las interacciones celulares y su entorno, hace que volvamos de nuevo la vista al entorno tisular que sustenta muchos procesos que ahora la neurociencia enfatiza.

En este contexto y con base en la necesidad que siguen teniendo los científicos de demostrar la inervación de numerosos órganos y tejidos, en una gran variedad de modelos animales y condiciones experimentales, el objetivo de este trabajo fue rescatar un método que hemos comprobado es muy constante para demostrar la inervación, y lo hemos adaptado a cortes por parafina y en un protocolo de goteo para hacerlo mas económico y fácil de adoptar en el trabajo de rutina.

\section{MATERIAL Y MÉTODO}

Material biológico: Se utilizaron seis especies.

Pez: Larvas de lenguados de California de la especie Paralichthys californicus de diferentes edades provenientes del CICESE (Centro de Investigación Científica y Educación Superior de Ensenada Baja California), se anestesiaron y sacrificaron por inmersión en una solución acuosa de Sulfato Metano Tricaina al 1:5000.

Anfibio: Dos machos adultos de la especie Ambystoma mexicanum provenientes del Lago de Xochimilco, D. F. se anestesiaron y sacrificaron por inmersión en una solución acuosa de Sulfato Metano Tricaina al 1:5000.

Reptil: Gecko hembra adulta de la especie Hemidactylus turcicus, colectada en el Morro de la Mancha, Veracruz, y dos lagartijas del género Sceloporus colectadas en el pedregal de San Angel, D.F., se anestesiaron con vapores de cloroformo y se decapitaron.

Ave: Dos aves machos del género Gallus, provenientes de la Facultad de Medicina Veterinaria y Zootecnia, UNAM, se anestesiaron con vapores de cloroformo, y se sacrificaron por dislocación cervical.
Mamífero: Dos ratas Wistar (Rattus rattus) macho de 30 días de edad, provenientes del Bioterio de la Facultad de Ciencias, UNAM, se anestesiaron con vapores de cloroformo y se sacrificaron por dislocación cervical.

De todos los organismos se disecaron las glándulas adrenales junto con el riñón o la gónada y fragmentos de 0,5 cm2 de piel de diversas partes del cuerpo; con excepción de las larvas de pez que se procesaron completas.

Fijación. Para la aplicación de éste método se utilizó la fijación de rutina con formaldehído diluido al $10 \%$ en agua bidestilada (v/v). Se probó también con paraformaldehído al $4 \%$ y fijador de Bouin con buenos resultados.

Corte. El procedimiento por congelación, para manejar los cortes por flotación, es el método clásico para la mayoría de las técnicas argénticas, sin embargo en este trabajo se utilizaron cortes de $7 \mu \mathrm{m}$ de los tejidos incluidos en parafina. Se obtuvieron así ventajas como evitar el deterioro del corte, definir el grosor del tejido más conveniente para ver tractos y el trayecto de algunas fibras, obtener cortes seriados, hacer más reproducible el método y optimizar el tiempo.

\section{Reglas generales para el uso de los métodos de pla- ta en cortes realizados por el método de inclusión en para- fina.}

1. El agua que se utilice para la realización de las técnicas de impregnación metálica, para preparar los reactivos así como para lavar el material debe ser siempre destilada o bidestilada. Debe comprobarse antes que dicha agua no precipite la plata.

2. La cristalería y los frascos que contendrán los reactivos metálicos, deben estar rigurosamente limpios, enjuagados siempre con agua destilada para evitar la presencia de sales que puedan precipitar la plata.

3. Eliminar rigurosamente el empleo de recipientes e instrumentos metálicos, sustituyéndolos por materiales de vidrio. El manejo de los portaobjetos será siempre con pinzas de plástico

4. Usar siempre reactivos de la máxima pureza y de marcas acreditadas.

5. Después de cada manipulación las pinzas de plástico deben enjuagarse siempre con agua destilada para evitar precipitados.

6. Se debe comprobar sobre fondo blanco y negro que las soluciones de plata y oro estén libres de precipitado antes de gotearlas sobre los cortes.

7. Los recipientes que contengan las soluciones metálicas deben taparse siempre y protegerse de la luz, igual que la cámara húmeda.

8. Para guardar las soluciones de plata y oro, usar frascos 
ámbar de boca angosta y tapón de vidrio, plástico o baquelita, nunca metálico.

9. Limpiar, siempre que se usen, la boca de los frascos que contienen soluciones de plata y oro con un lienzo limpio por dentro y por fuera para evitar que se formen precipitados.

Manejo de los cortes por parafina por el método de goteo. En cortes incluidos en parafina (según la técnica habitual) se recomienda:

a. Adherir los cortes a los portaobjetos preparados con poli-Llisina.

b. Aplicar los reactivos metálicos (plata y oro) en gotas sobre el tejido, en una cámara húmeda (como la que se usa para inmunohistoquímica).

c. Utilizar vasos de Koplin o de precipitados de $100 \mathrm{~mL}$ para los demás reactivos y para los lavados.

d. Escurrir bien y enjuagar la parte posterior de los portaobjetos para evitar el arrastre de los reactivos impregnadores y reductores. Se rodea con papel filtro el corte, sin tocarlo, para enjugar el excedente de reactivo.

\section{Preparación de los reactivos.}

\section{Nitrato de plata al $20 \%$}

- Mezclar $2 \mathrm{~g}$ de nitrato de plata con $10 \mathrm{~mL}$ de agua destilada (aproximadamente para 10 preparaciones).

- De preferencia la solución debe prepararse cada vez que se va a usar, pues por ser concentrada la plata tiende a precipitarse. Se puede guardar en frasco ámbar protegido del calor y la luz y revisar sobre fondo blanco que no tenga precipitados antes de usar.

Nitrato de plata al $10 \%$.

- Mezclar $1 \mathrm{~g}$ de nitrato de plata con $10 \mathrm{~mL}$ de agua destilada.

Se puede preparar y guardar en frasco ámbar protegido del calor y la luz y revisar sobre fondo blanco que no tenga precipitados antes de usar.

\section{Carbonato de sodio a saturación}

- A 1 L de agua destilada agregar carbonato de sodio hasta formar una solución saturada.

Guardar en frasco ámbar o claro, de preferencia se debe tener siempre preparado con anticipación en cantidad suficiente.

\section{Carbonato de plata hiperfuerte}

- Mezclar $10 \mathrm{~mL}$ de nitrato de plata al 10\% con carbonato de sodio saturado hasta que deje de formarse precipitado. Se deja sedimentar y se decanta. Se conserva sólo el precipitado con el mínimo de sobrenadante.
- Lavar cuatro veces el precipitado de carbonato de plata con abundante agua destilada. Se decanta cada vez y se conserva sólo el precipitado con el mínimo de sobrenadante. Se guarda un poco de precipitado en la punta de una pipeta perfectamente limpia (puede ser de vidrio o plástico, de preferencia desechable).

- Disolver el precipitado añadiendo amoníaco gota a gota y evitando su exceso.

- Añadir agua destilada hasta recuperar la cantidad inicial (aproximadamente $10 \mathrm{~mL}$ ).

- Agregar el precipitado de carbonato de plata guardado en la pipeta, para neutralizar el amoníaco que pudiera haber en exceso y filtrar.

Se recomienda preparar sólo la cantidad que se va a utilizar.

Formol al 25\%. El formol al 25\% para esta técnica se prepara con una parte de formaldehido $(250 \mathrm{~mL})$, tres partes de agua destilada $(750 \mathrm{~mL})$. Se recomienda preparar con anticipación un litro y guardar.

Procedimiento:

1. Fijación en formol al 10\%, de 8 a 15 días.

2. Cortes por parafina de 6 a $10 \mu \mathrm{m}$, a menos que se requieran, no se recomiendan cortes muy delgados pues se pierde el curso de las fibras nerviosas.

3. Lavar tres veces con agua destilada.

4. Sumergir los cortes en agua piridinada (XXV gotas de piridina en $50 \mathrm{~mL}$ de agua destilada), $15 \mathrm{~min}$.

5. Lavar tres veces con agua destilada. Secar el portaobjetos con papel filtro evitando tocar el tejido.

6. Impregnación con gotas de nitrato de plata al $20 \%$ durante 24 h, en cámara húmeda a temperatura ambiente. Escurrir y secar el portaobjetos con papel filtro evitando tocar el tejido. 7. Pasar los cortes uno por uno a formol al $25 \%$, tres cambios. Cada vez, enjuagar la parte posterior del portaobjetos y enjuagar la parte de enfrente con papel filtro, sin tocar el corte. Esta operación debe ser muy cuidadosa para evitar el depósito de precipitado en el tejido, sobre todo al pasar de la plata al formol. Cambiar inmediatamente el formol si se observa lechoso (con precipitado).

8. Impregnación con gotas de plata hiperfuerte recién preparada y filtrada hasta que los cortes tomen color amarillento (ámbar) entonces se escurre. Dependiendo de los resultados puede hacerse una segunda impregnación del mismo modo. Sólo se cubre el tejido con unas gotas de esta solución sin que se derrame y se mantiene en la cámara húmeda.

9. Lavar rápidamente con agua destilada. 
10. Diferenciar en una solución débil de ácido acético, hacer dos cambios (agua $40 \mathrm{ml}+\mathrm{V}$ gotas de ácido acético).

11. Lavar rápidamente en agua destilada.

12. Virar con cloruro de oro al $0,2 \%$, aproximadamente 1 $\mathrm{mL}$ para cada preparación (con dos o tres cortes), en cámara húmeda cubriéndola de la luz, durante $15 \mathrm{~min}$. 13. Remoción del metal excedente con hiposulfito de sodio al 5\% durante $5 \mathrm{~min}$. 14. Lavar con agua destilada. 15. Deshidratar con alcoholes graduales.

16. Aclarar con xilol, montar y cubrir con resina sintética.

El paso 12 es opcional. Además, se debe tener preparado el formol al $25 \%$ en suficiente cantidad con anticipación, pues si se enturbia debe eliminarse y no usarse con otros cortes.

\section{RESULTADOS}

Las impregnaciones obtenidas se pueden observar en las Figuras 2 y 3. Corpúsculos sensitivos, nervios, axones mielinizados y no mielinizados se observan en color negro con un fondo violeta si se hace la entonación áurica (paso 12) si no, el tono del fondo es dorado. Aunque no es una técnica específica para argentafinidad, las células argentafines se impregnan intensamente, en color negro las de noradrenalina y pardas las de adrenalina.

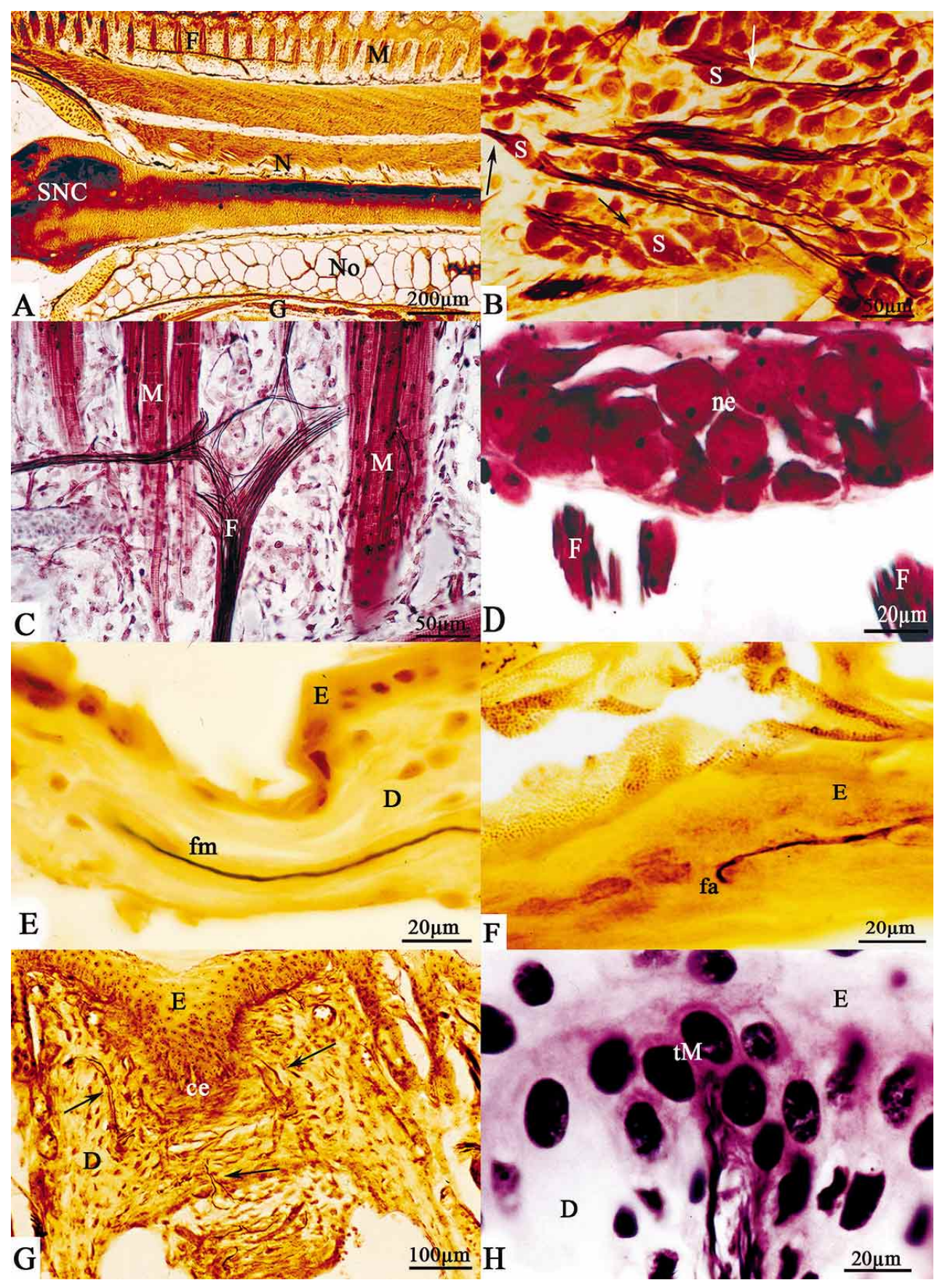

Fig. 2. Fotomicrografías de diversas estructuras de larva de Paralichtys californicus (A-C) y de piel de vertebrados (D-H) impregnadas con la técnica de Llombart (con entonación áurica en color púrpura). A. Corte sagital de larva de lenguado. Se observan Sistema Nervioso Central (SNC), notocorda (No), ganglios $(\mathrm{G})$ y nervios $(\mathrm{N})$ espinales, fascículos nerviosos (F) en músculo subtegumentario (M). B. Ganglio espinal de lenguado, se observan las neuronas sensitivas (S) y sus prolongaciones (flechas). C. Fascículos nerviosos (F) entre haces musculares (M) subtegumentarios. D. Fascículos nerviosos (F) hacia un neuromasto (ne) en la epidermis de $A$. mexicanum. E. Fibra nerviosa mielínica (fm) en dermis (D) de piel de Hemidactylus. F. Fibra nerviosa amielínica (fa) en epidermis (E) de Hemidactylus. G. Terminaciones nerviosas (flechas) en el collar epidérmico (ce) de una vibrisa nasal de Rattus. H. Terminación nerviosa tipo Merckel (tM) en la dermis (D) de cojinete plantar de Rattus. Epidermis (E). 


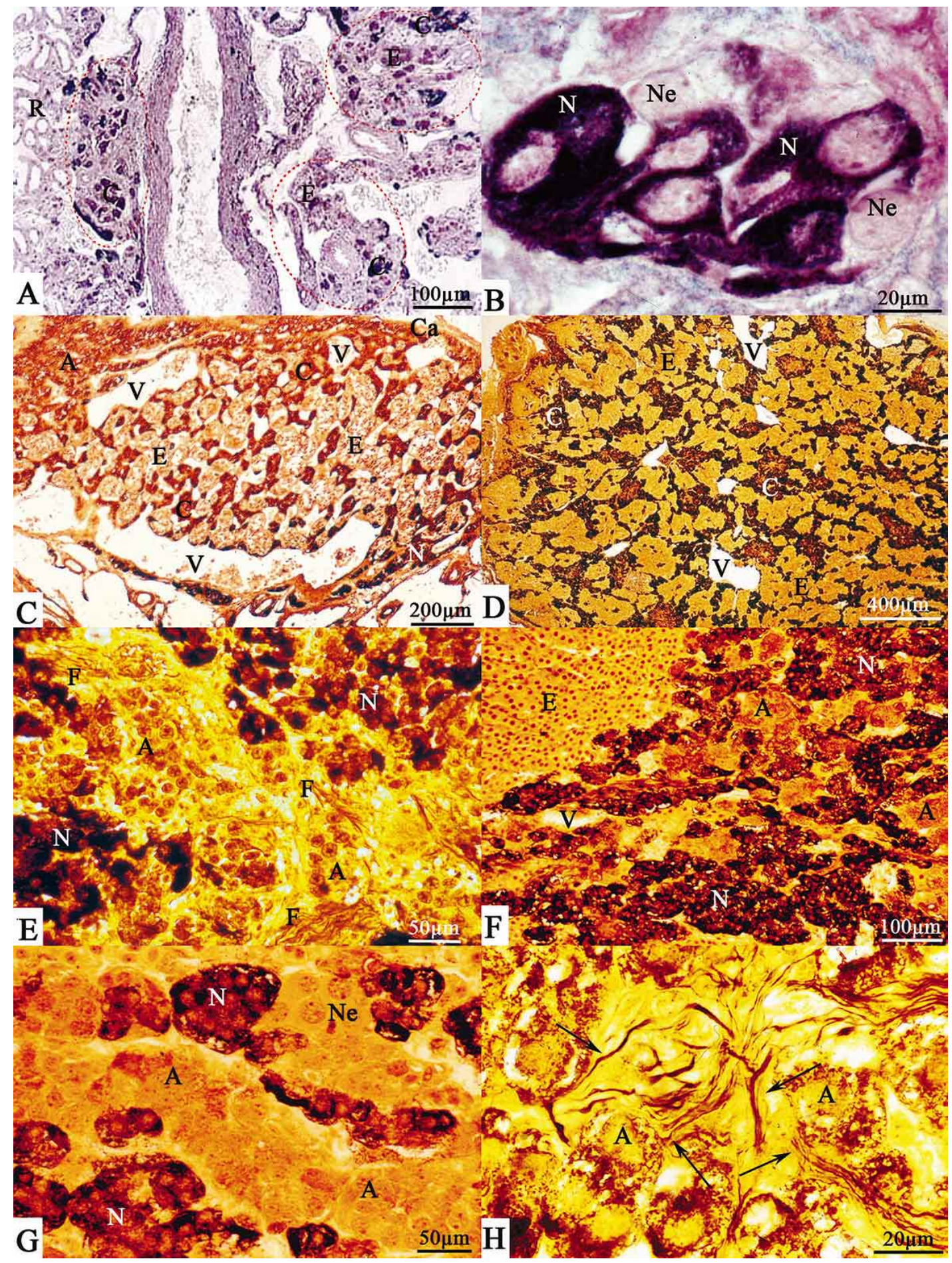

Fig. 3. Fotomicrografías de glándulas adrenales de vertebrados impregnadas con la técnica de Llombart (con entonación áurica en color púrpura), demuestran tanto el tejido esteroidogénico (E) como el cromafín (C), en este último se diferencian las células elaboradoras de noradrenalina $(\mathrm{N})$ de las de adrenalina (A), fibras nerviosas $(\mathrm{F})$ y neuronas (N). A. Islotes adrenales (círculos punteados) de Ambystoma. B. Células elaboradoras de noradrenalina predominantes en Ambystoma. C. Adrenal de Sceloporus. D. Adrenal de Gallus. E. Células de noradrenalina y adrenalina en tejido cromafín de Gallus. F. Adrenal de Rattus. G. Células de noradrenalina y adrenalina en medula adrenal de Rattus. H. Las células de adrenalina de la médula adrenal de Rattus, muestran gran inervación. Sinusoides $(\mathrm{V})$, cápsula $(\mathrm{CA})$, riñón $(\mathrm{R})$. 


\section{DISCUSIÓN}

En general todas las estructuras del cuerpo están inervadas, y normalmente se requieren muchos estudios, algunos de ellos sofisticados y costosos, para analizar dicha inervación. La observación de las fibras y terminaciones nerviosas entre los tejidos de los diversos órganos es un reto grande ya que generalmente quedan enmascaradas entre los constituyentes tisulares y ninguna técnica de rutina permite visualizarlas.

Seleccionamos entre muchas técnicas argénticas una que nos permitiera ver con claridad las fibras y terminaciones nerviosas periféricas, dentro de su entorno tisular. $\mathrm{La}$ técnica de Llombart cumplió satisfactoriamente con las expectativas necesarias para este fin. En todos los tejidos probados se obtuvieron resultados aceptables. En general permitió observar nervios y fascículos nerviosos, y en particular analizar las terminaciones nerviosas prácticamente en todos los tejidos, y demostrar diversos tipos de corpúsculos sensitivos en la piel.

La aplicación de la técnica de Llombart para comparar la inervación en la glándula adrenal de vertebrados, no sólo cumplió este objetivo sino que sin ser una técnica para argentafinidad, demostró en forma diferencial no sólo al tejido cromafín (argentafín) respecto al esteroidogénico, sino también permitió reconocer claramente tanto las células elaboradoras de adrenalina como las células elaboradas de noradrenalina (Unsicker, 1973; Accordi \& Gallo, 1982), y además todos los elementos de la glándula, como las neuronas simpáticas y su vascularización. La alta definición de las células cromafines resultó en nuestra experiencia, superior a la ofrecida por otras técnicas específicas para argentafinidad o cromafinidad.

Para hacer el estudio comparativo de la glándula adrenal es indispensable hacer un buen mapeo de los dos tejidos que la constituyen (cromafín y el esteroidogénico) en los animales que los tienen separados y dispersos (peces y anfibios) así como realizar una clara diferenciación de ellos en los organismos que los tienen complejamente entremezclados (como es el caso de los reptiles y las aves) (Leake, 1975; Paniagua \& Nistal, 1983). La demostración de todos los elementos que constituyen la glándula adrenal requiere de varios métodos específicos entre ellos técnicas para lípidos, para cromafinidad, para neuronas, para fibras y terminaciones nerviosas o bien histoquímicas o inmunohistoquímicas particulares. En todos los casos mencionados se marcan estructuras, sustancias o moléculas específicas pero se pierde el panorama tisular. Asimismo hay que utilizar diversas metodologías y reactivos que hacen muy costosos los estudios de esta naturaleza. Al utilizar una sola técnica como la impregnación argéntica de Llombart podemos poner de manifiesto simultáneamente la mayoría de los elementos que constituyen la glándula, con excelente detalle y gran contraste, lo que permite: hacer una buena descripción histológica; realizar análisis morfométricos y optimizar los recursos, incluyendo el material biológico.

Por la alta definición de cada estructura, esta técnica es muy favorable para hacer estudios morfométricos tanto a nivel de sus tejidos (cromoargentafín y esteroidogénico) como a nivel celular (células elaboradoras de adrenalina, de noradrenalina y neuronas simpáticas) o subcelular (gránulos intracitoplásmicos, terminaciones nerviosas).

Cabe mencionar, que está técnica no sólo nos ha permitido reconocer las células cromafines en la glándula adrenal de los vertebrados, sino también demostrar células argentafines en el páncreas, el intestino y los riñones entre otros órganos (resultados no mostrados).

Por todo lo anterior proponemos a la técnica de Llombart como un método de rutina en todos aquellos protocolos científicos o diagnósticos, que en primera instancia pretendan demostrar la inervación de cualquier órgano o la presencia de células argentafines (cromafines) en los tejidos.

Es importante recalcar, que como cualquier procedimiento de histoquímica o inmunohistoquímica, los métodos de plata exigen pureza en los reactivos y ejecución exacta del protocolo para obtener resultados consistentes y repetibles.

\section{CONCLUSIONES}

Las principales adaptaciones que se hicieron a la técnica original fueron: a) cambiar los cortes por congelación por cortes en parafina, b) hacer la impregnación por goteo en una cámara húmeda como en la imunohistoquímica y c) de manera opcional, aplicar cloruro de oro para la entonación áurica, que generalmente se omite por el costo del oro, pero al aplicarlo en gotas resulta muy económico.

La adaptación de la Técnica de Llombart en cortes por parafina y probada con buenos resultados en la piel de diferentes vertebrados, es sugerida también como una técnica de rutina en cualquier protocolo que requiera demostrar estructuras del SNP (ganglios, nervios, fascículos, fibras, terminaciones nerviosas y corpúsculos sensitivos) en cualquier parte del organismo con una alta definición y sin perder el entorno tisular. 
La aplicación de la técnica de Llombart resultó muy útil para la demostración simultánea de todos los componentes histológicos y citológicos de la glándula adrenal de vertebrados. Especialmente las células elaboradoras de adrenalina y de noradrenalina, aun cuando no es una técnica específica para argentafinidad.

Finalmente podemos decir que mediante el trabajo interdisciplinario y colaborativo, los métodos argénticos refinados, como el de Llombart, prometen seguir siendo una herramienta bioanalítica vigente para el estudio de sistema nervioso central y periférico, al ofrecer detalles estructura- les sumamente específicos y simultáneamente demostrar las características del ámbito tisular, gracias a su gran sensibilidad por las estructuras celulares y tisulares, a su marcaje de alto contraste y con la ventaja de que la impregnación de las estructuras no decae a través del tiempo.

\section{AGRADECIMIENTOS}

Agradecemos a la Bióloga Mónica Buendía Padilla por su apoyo técnico.

RIVAS, M. P.; CHAVIRA, R. C. T. \& ORTIZ, H. R. Adaptation of the Llombart's silver impregnation technique for demonstration of nerve fibers in any tissue in paraffin sections. Int. J. Morphol., 32(3):973-980, 2014.

SUMMARY: In Biological research is still necessary for the demonstration of the peripheral innervation in numerous tissues and organs. The aim of this study was to rescue and modernize one of the most consistent methods that we have tried to demonstrate peripheral innervation. Llombart's technique for nerve fibers was adapted by paraffin cuts of $7 \mu \mathrm{m}$ in different animal tissue. The silver impregnation was done by dripping in a moist chamber. It was demonstrated in a constant, precise and serial form, nerve terminations, and sensorial corpuscles, neurons, and peripheral nerve fibers. Despite being highly specific to nerve fibers, the technique does not sacrifice tissue panorama so it gives beautiful images set. Without being a technique to argentaffin structures, it clearly shows two types of argentaffin cells in the adrenal glands. The addition of the metal reactive in droplets and in a humid chamber provides a very economical variant.

KEY WORDS: Silver impregnation; Nerve fibers; Peripheral innervation; Argentaffin cells.

\section{REFERENCIAS BIBLIOGRÁFICAS}

Accordi, F. \& Gallo, V. P. Adrenaline-, noradrenaline- and small granule- containing cells in the adrenal gland of Discoglossus pictus (Amphibia, Anura). J. Anat., 135(Pt. 1):5-12, 1982.

Fuxe, K. \& Agnati, L. F. Receptor-receptor interactions in the central nervous system. A new integrative mechanism in synapses. Med. Res. Rev., 5(4):441-82 1985.

Costero, I. Crónica de una vocación científica. México, Editores Asociados, 1977.

De Carlos, J. A. \& Borrell, J. A historical reflection of the contributions of Cajal and Golgi to the foundations of neuroscience. Brain Res. Rev., 55(1):8-16, 2007.

Grizzle, W. E. Theory and Practice of Silver Staining in Histopathology. J. Histotechnol., 19(3):183-95, 1996.

Jacobson, M. D. Reactive oxygen species and programmed cell death. Trends Biochem. Sci., 21(3):83-6, 1996.

Kiernan, J. A. On Chemical Reactions and Staining Mechanisms. In: Kumar, G. L. \& Kiernan, J. A. (Eds.). Education Guide - Special Stains and H \& E. 2nd ed. Carpinteria, Dako North America, 2010 .

Kuhar, M. J.; Unnerstall, J. R. \& De Souza, E. B. Receptor mapping in neuropharmacology by autoradiography: some technical problems. NIDA Res. Monogr., 62:1-12, 1985.
Leake, L. D. Comparative Histology: An introduction to the microscopic structure of animals. London, Academic Press, 1975.

Nauta, W. J. Selective silver impregnation of degenerating axons in the central nervous system. Stain Technol., 27(3):175-9, 1952.

Paniagua, R. \& Nistal, M. Introducción a la histología animal comparada. Barcelona, Labor Universitaria, 1983.

Peters, A. Golgi, Cajal, and the fine structure of the nervous system. Brain Res. Rev., 55(2):256-63, 2007.

Switzer, R. C. 3rd. Application of silver degeneration stains for neurotoxicity testing. Toxicol. Pathol., 28(1):70-83, 2000.

Unsicker, K. Fine structure and innervation of the avian adrenal gland. I. Fine structure of adrenal chromaffin cells and ganglion cells. Z. Zellforsch. Mikrosk. Anat., 145(3):389-416, 1973.

\author{
Dirección para Correspondencia: \\ Patricia Rivas Manzano \\ Departamento de Biología Comparada \\ Facultad de Ciencias \\ Universidad Autónoma de México (UNAM) \\ México D.F. \\ MÉXICO
}

Email: patirmanzano@gmail.com

Recibido : 31-03-2014

Aceptado: 27-06-2014 